\title{
WACSeries Op-Ed
}

No. 3 - April 2021

\section{Branding Tips for Civil Society Organisations}

By George Neba
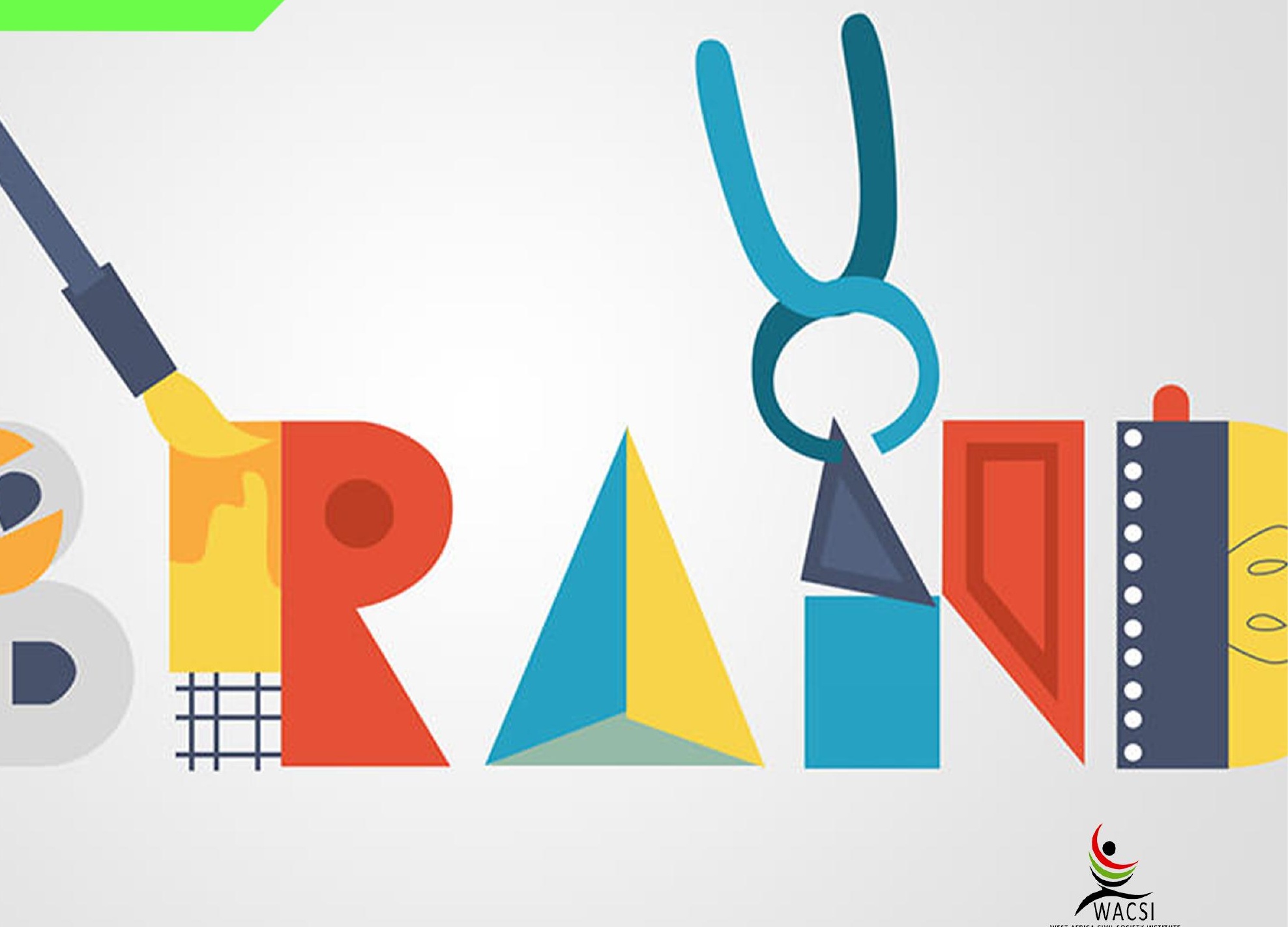


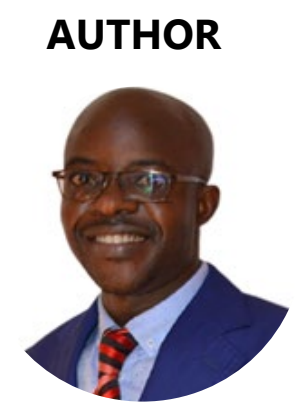

George Neba is a personal branding specialist from Cameroon, with a mandate, "to empower impactdriven organisations, socially-conscious game-changers, and corporate professionals who do go, do better, by leveraging the power of personal branding." He achieves this by grooming them with resilient skills to identify, activate, own, elevate, and monetize their authentic brands, gain instant recognition in their niche, position themselves as thought leaders, and amplify their visibility, influence, and impact, through Brandway Academy (BRAC), where he is the founder and doyen. Volunteering is his modus vivendi, with over 50 volunteer missions to his credit. In August 2019, he was crowned Volunteer Ambassador by the Noela Lyonga Foundation, Buea, Cameroon. He is also very obsessed about peace-building as a unique way to sustainable development, especially when it comes to upholding socio-economic justice amongst vulnerable African youths and women. He has a knack for summarising important human insights into short, memorable, and thought-provoking statements, aimed at positively-transforming minds and lives. George Neba is an alumnus of NCSAPD (2014), CLA (2015), YALI (2016), ECI (2017), UCYE (2018), AYUC (2019), AGLA (2020), REPAIR (2020), CUBLEF (2020), etc. - where he has held different posts of responsibility and led different projects.

\section{Editorial Team}

Jimm Chick Fomunjong - Head, Knowledge Management Unit, WACSI

Nancy kankam Kusi - Programme Officer, Knowledge Management Unit, WACSI

\section{About WACSI}

The West Africa Civil Society Institute (WACSI) was created by the Open Society Initiative for West Africa (OSIWA) to reinforce the institutional and operational capacities of civil society in the region. WACSI also serves as a resource centre for training, research and documentation, experience sharing and political dialogue for CSOs in West Africa.

\section{About WACSeries}

WACSeries are analytical periodic write-ups on topical themes and issues relevant to West Africa. These write-ups provide experts, researchers and practitioners a space to reflect, analyse and posit views and recommendations on emerging issues and debates.

The WACSeries Op-Eds are thought provoking and intellectually engaging write-ups that provide critical reflections and analysis of issues relevant to civil society and development in West Africa.

\section{Objectives of WACSeries}

- To raise awareness on key issues in West Africa;

- To generate debates and discussions on these issues;

- To proffer recommendations on civil society involvement in advocacy;

- To provide recommendations to policy makers. 


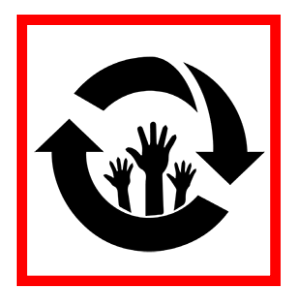

\title{
Branding Tips for Civil Society Organisations
}

\author{
(C) WACSI 2021
}

All rights reserved. No part of this report may be used or reproduced in any manner whatsoever without written permission of the Institute except in the case of brief quotations embodied in critical articles and reviews. The Institute requests the use of information in this report be registered with them for impact assessment purposes.

\section{Disclaimer:}

WACSI accepts no responsibility for suitability of any materials submitted by the contributor of this publication. WACSI assumes no responsibility or liability for errors or inaccuracies. The contributor accept all responsibility for opinions expressed. Use of this research report constitutes acceptance and understanding of these disclaimers.

For more information, write to:

West Africa Civil Society Institute (WACSI) No. 9 Bamboo Street, East Legon P.O. Box

AT 1956, Achimota Accra, Ghana

Email: research@wacsi.org Tel: +233 (0) 302550224

Cite as:

Neba, G. (2021). Branding Tips for Civil Society Organisations, WACSeries, Op-Ed $\mathbf{N}^{\circ}$ 3, West Africa Civil Society Institute, Accra, Ghana.

To contribute to this publication,

contact : research@wacsi.org $+233(0) 501440545$ 


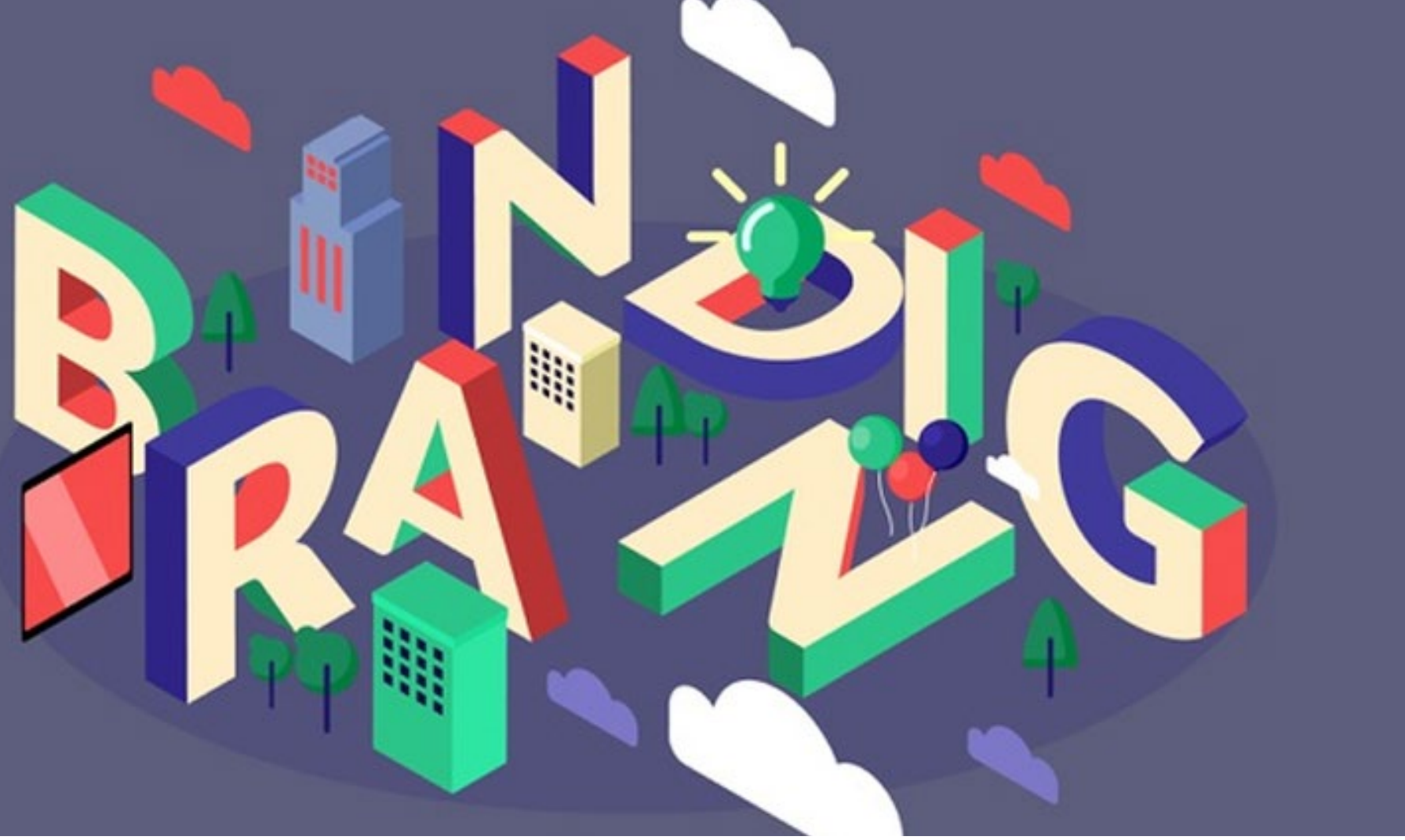

Image by Sharmila Kayal via https://adamasuniversity.ac.in/

\section{Introduction}

There is no gainsaying that branding plays a central role in ensuring the success of any corporate organ, its product(s) and/or service(s) in any market milieu, notwithstanding the challenges. When done properly, branding not only creates instant recognition for an organisation in a given niche or industry, it also builds irresistible loyalty in the minds of clients, and thus amplifies community influence, social impact, and income of the said organisation.

Branding may be defined in our context as, an organisation's ability to tell its story in a manner that creates positive experiences, attracts loyalty to its mission, fosters corporate philosophy and assures stakeholders about the significance of its interventions.

Branding is therefore an active rather than passive exercise. It requires a conscious and consistent effort by the organisation. In recent years, corporate branding seems to be predominantly undertaken by for-profit business entities; with little or no effort being invested in the branding of not-for-profit businesses. Nonetheless, if what is good for the goose is also good for the gander, then corporate branding is as essential for civil society organisations (CSOs) as it is for profitmaking entities. It is essential for CSOs because it is a vital means to get development stakeholders to be more informed about their work. This would enable informed development stakeholders to support an organisation's mission, programmes, and interventions.

Furthermore, branding can stimulate a sense of belonging from the general public and the civil society sector and promote resilient organisational cohesion .

Thus, any CSO that intends to benefit from the myriad of opportunities that branding offers, must consciously build its brand. And the stronger the brand, the better. 


\section{A. Importance of Branding to CSOs}

\author{
Why then is branding relevant to civil society \\ organisations?
}

\section{Branding builds a professional identity}

When building a corporate brand, everything you do either adds to or subtracts from it. Because you never have a second chance to make a first impression, it is advisable to make yours not only a memorable one, but one that reflects your organisation's true brand identity and singles you out from others. Every civil society organisation has its niche, its unique offering and key entry points points (or points of interaction) through which they inter-connect with their audience in delivering services and/or products. Thus, branding is very important in creating a remarkable connection with your audience and in raising the level of recognition and professionalism of your organisation in their eyes and minds, over time.

\section{Branding amplifies corporate visibility}

Branding does not only simplify the recognition of your brand by your audience, but also creates an elevated level of awareness about your organisation and provides it with a noteworthy presence in your industry. Nowadays, development stakeholders have a wide variety of CSOs running related projects or programmes. To portray that your organisation is unique in what it does, branding distinguishes you from others and helps you to specifically communicate your achievements and impacts in a way that makes you stand out from the masses. Stakeholders, especially donors expect to see the ultimate results of the problem that you are solving and branding will help you to live up to those expectations.

\section{Branding brews credibility and loyalty}

Branding expands your circle of influence. It helps organisations to win the trust of its followers and contributes to strengthen followers' loyalty to the organisation. Consequently, the more credible you become, the more loyalty you build and the more your brand equity and value are boosted.

\section{Branding strengthens thought leadership}

The easiest way for your organisation to become a go-to-expert in your industry is through branding. It permits you to display your prowess and familiarity regarding your area of focus. This will draw the attention of your audience to explore your potentials. As such, you easily build a community of like-minded constitutents who value and solicit your expertise. This presents an opportunity to make you an authority in your industry; as many heads will turn to you for reliable responses to thought-provoking questions in your specialty.

\section{Branding facilitates mobilisation of resources}

Once you have established thought leadership in your sector (through your branding prowess), that will further open up portals for your organisation to easily source for diverse resources; both locally and internationally, from individuals as well as institutions and most importantly, through internally generated

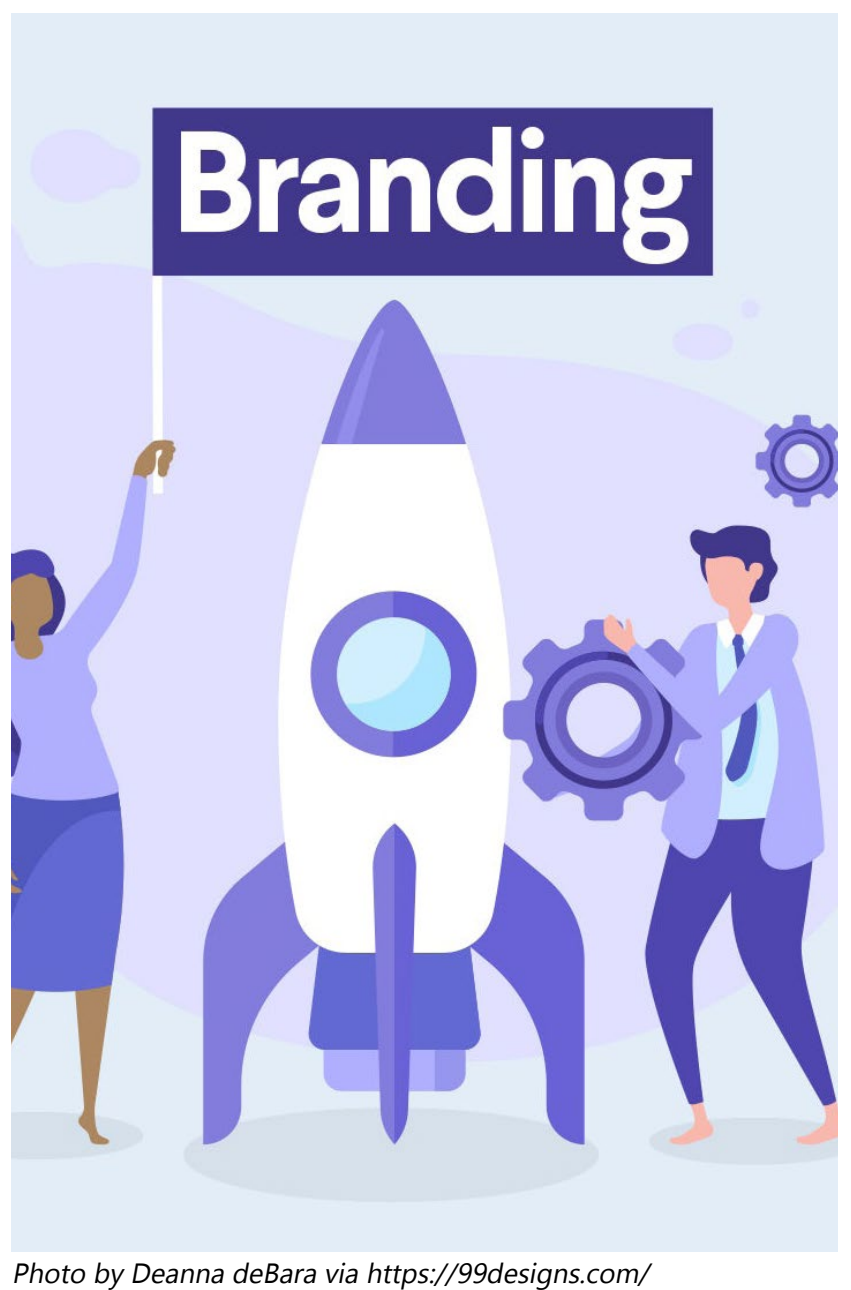


means. This is because thought leadership increases your brand value and fosters your negotiation and bargaining power. Furthermore, investors get attracted to you, given that funders prefer organisations with a track record of leadership and palpable results in their niche. This will result from the fact that, through effective-results-driven branding, your organisation would have developed a huge network of loyal advocates who instill trust in the minds of (potential) donors or partners.

Also, branding attracts talented professionals from your industry into your team, since people often wish to associate with well-respected and recognised brands. Moreover, other stakeholders may request for your mentorship, coaching, consultancy, tutelage, and/ or other valuable partnerships.

\section{Branding fosters reputation management}

These days, branding provides you with a better option of handling the challenge of reputation damage; one of the foremost risks which most organisations contend with, both offline and online. Research depicts that reputation risk is rated as much more important than other strategic risks and that loss of revenue is the biggest impact of reputation risk. So, investing in branding can limit any damage on your brand image.

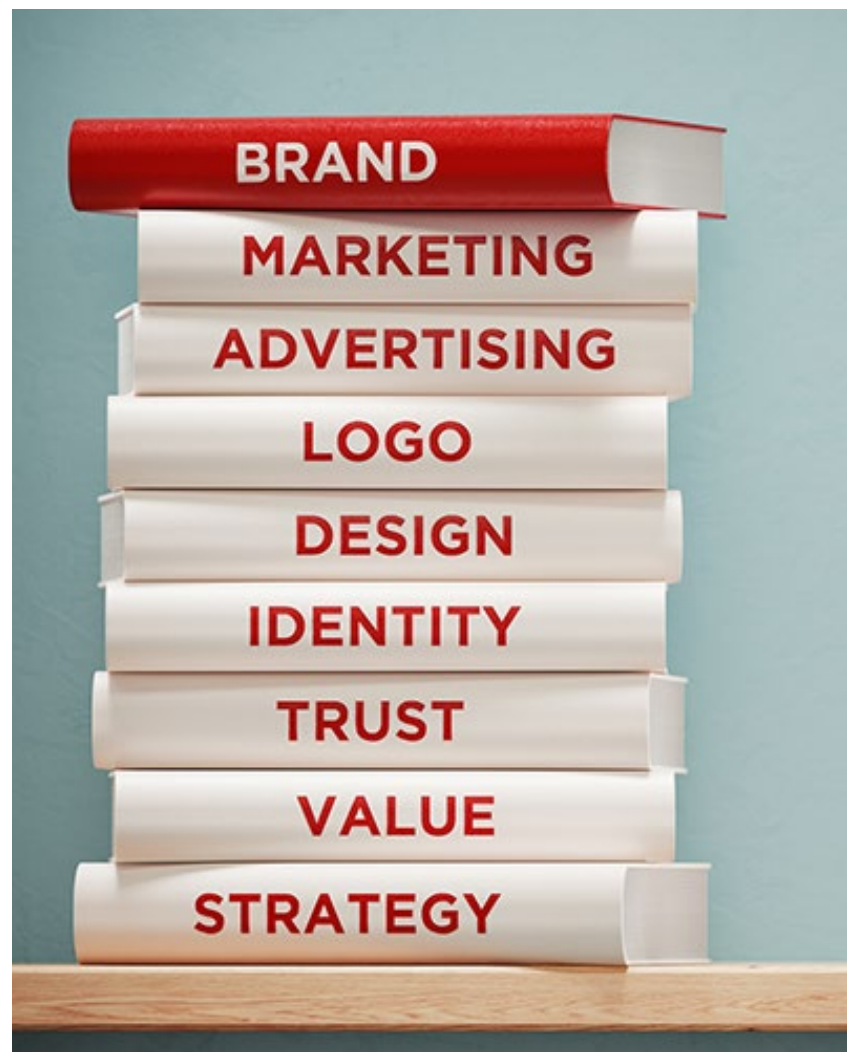

Image Mark Schmukler via https://marketinginsidergroup.com/

\section{B. Challenges Civil Society OrganisationsFacewith Branding and Ways of Surmounting Them}

Although corporate branding is becoming more and more essential than ever, most CSOs do not have sufficient clarity on how to build a robust brand. A few who do, encounter challenges worth overcoming. Below are some hurdles which CSOs grapple with in their branding journey and the techniques they can apply to surmount them, to develop an attractive corporate brand.

\section{i. Lack of a clearly defined strategic organisational plan}

Some civil society organisations do not have a welldefined strategic (or long-term) plan. Also, some do not have laid down principles on which to operate. Even when available, they are not compelling enough, or they are poorly implemented. Thus, organisations find it difficult to influence the desired social change. They sometimes find it challenging to explicitly define their niche, differentiate themselves, resonate with stakeholders and inspire their audience.

Thus, organisations need to commence by recognising and designing a strategic plan for themselves. This lays a firm foundation for future organisational success. The existence of a solid organisational strategy (with clearly outlined mission, vision, values, goal and objectives) will enable an organisation to define and operationalise a successful branding philosophy (that is, your branding strategy, goal and objectives).

\section{ii. The mission drift phenomenon}

Maintaining brand relevance requires commitment and the intention to focus on your organisation's values, mission, and goal, if any. But regrettably, some CSOs deviate from this course, majorly due to the survival instinct whereby CSOs struggle with a dependency on donor funding. This impedes sustainability, distracts them from their missions, and encourages a short-term (often spontaneous) strategy of chasing funds, rather than focusing on interventions that foster their mission. This causes organisations to gradually lose relevance, hence, their brand image becomes adulterated and/or becomes less conspicuous over time. 


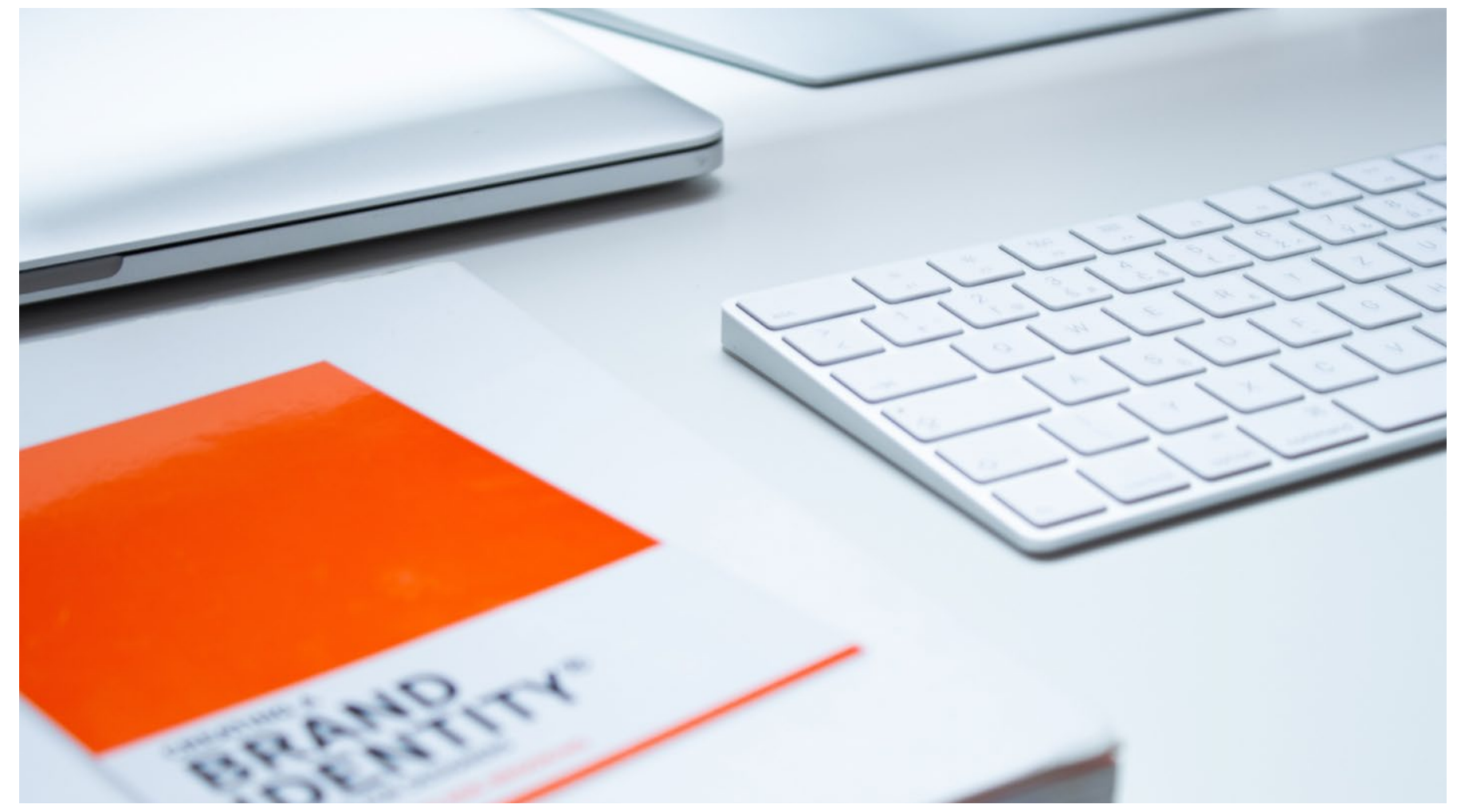

Photo by Patrik Michalicka on Unsplash

For CSOs to resolve the mission creep, they need to explore new complementary models or alternatives of generating financial resources. Examples of alternative revenue sources which CSOs could explore are: provision of consultancy services, leasing of organisational assets (like chairs, office space, halls, conference rooms, documented resources, etc.), hosting of events, membership subscription fees, becoming socially enterprising by running a forprofit venture to support social change, etc. This will facilitate institutional independence, rather than depending almost entirely on donor funding to run specific activities and projects.

New models of blended finance can include the creation of local trust funds through dues, fee-forservice activities, donor and private sector grants, endowments, and cost-risk-sharing partnerships. Such approaches to fundraising provide organisations with resources that catalyse their autonomy. This therefore helps organisations to stick to efforts geared towards accomplishing their mission and this further enables them to have a clear and consistent brand identity which they can promote over a long period.

\section{iii. Poorly skilled staff}

It is hard to succeed at branding without building your brand internally. That is, an ill-equipped or uninformed organisational team may ignore the essence of corporate branding if they do not know where they fit in it, or if they don't understand exactly what role they can play in enhancing the organisation's brand. Thus, this will impair the branding process, even if there exists a well-defined corporate philosophy and strategic plan.

This problem can best be resolved if every team member is involved in the branding effort. This can be better achieved through regular working sessions between management and employees whereby they constantly remind themselves about their role as stewards of the organisational brand, and the relevance of upholding same.

\section{iv. Ambiguous branding strategy}

Some CSOs unfortunately have an unreliable, unclear, and unfocused brand communication strategy. This makes their brand identity appear unprofessional and the brand message very confusing. 


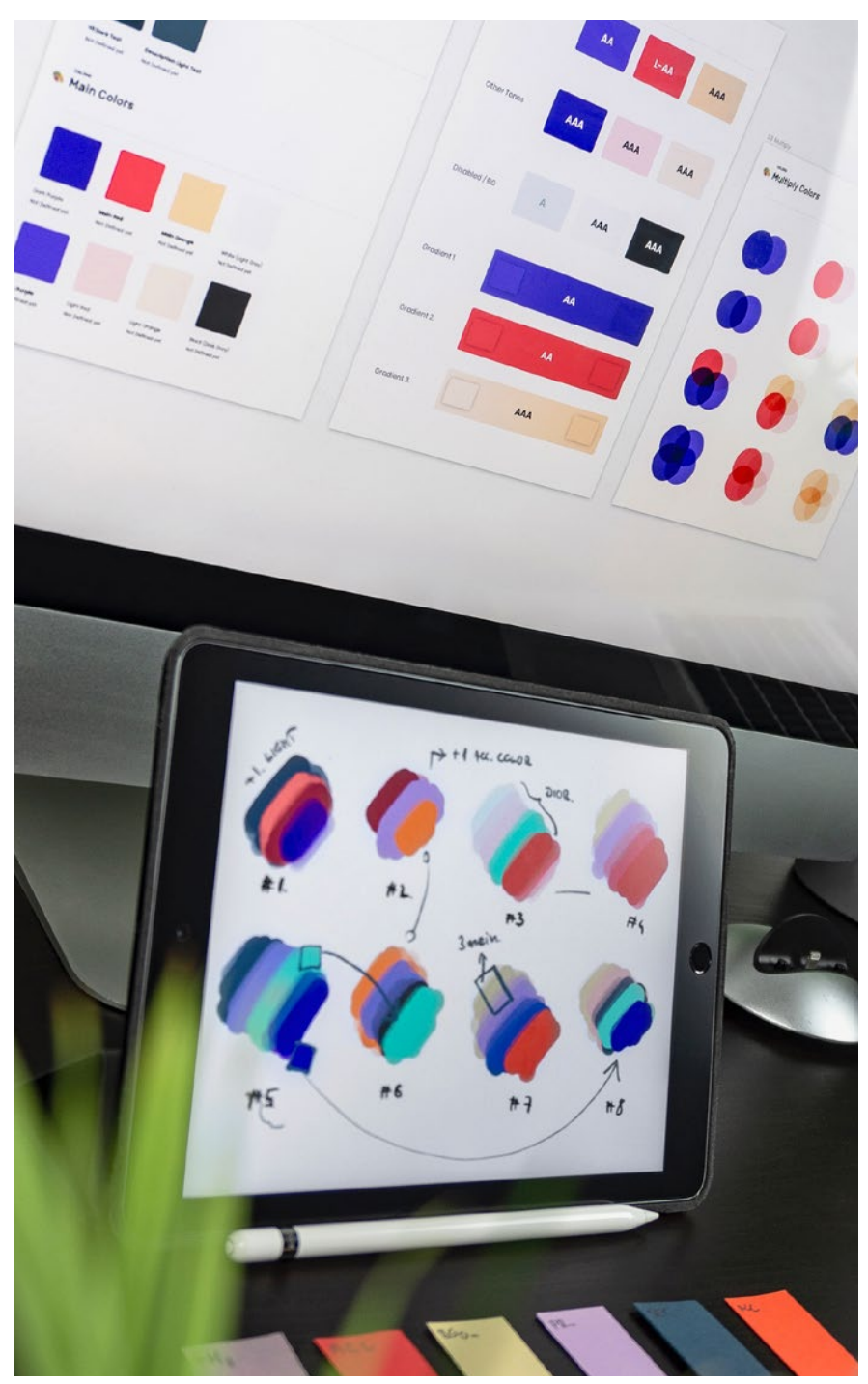

Photo by Balázs Kétyi on Unsplash

For organisations to avoid or address this, they need to consistently and coherently communicate their unique philosophy, project/programme interventions, and daily interactions with stakeholders using valuable content, to further deepen people's understanding about their mission. An organisation's brand message should be uniform in style and tone, and consistent in delivery. This means expressing your brand personality in a way that inspires confidence and portrays reliability in you, both online and offline.

That is, there should be synchrony at all levels: be it through physical meetings, social media, print material (such as flyers, brochures, newsletters, reports, etc.). Having a brand-portfolio strategy that yields synergy and clarity is very essential in building trust and loyalty, increasing awareness about your impact and raising your influence.

\section{v. Not leveraging branding as a durable asset}

In their quest for survival and short-term financial results, some organisations minimise the importance of treating their brand as a long-lasting investment. Such negligence to build a strong brand portfolio to foster long-term growth lessens the equity and value of the brand.

Thus, CSOs must understand that a corporate brand is an intangible asset, with goodwill that has a monetary value. Moreover, civil society organisations must realise that building a resilient brand that stands the test of time needs a commitment of time, money, effort and other resources as such brands are growth enablers.

\section{vi. Absence of a dependable media strategy}

Some organisations either neglect the aspect of building a strong media presence (especially digital media) or lack the proper content and dynamism to manage such a complex initiative. Furthermore, given that the audience is in control externally, the reputation of the CSO could be compromised, if not well-managed.

As such, a strong digital presence is also of the essence in building a formidable corporate brand. One of the ways of being readily available on the media is to solicit speaking engagements such as interviews, presentations at seminars, workshops, conferences, among others to exchange views or share your thoughts with your audience. In addition, through the use of technological tools like websites, emails, social media, you can effectively manage your reputation. This would entail monitoring, measuring and regulating the conversation in and around your organisation and responding to your stakeholders accordingly. This will ensure that what people perceive and say about you actually aligns with your brand personality. 


\section{QUICRKREAD}

- Civil Society Organisations need to have a well-defined strategic (or long-term) plan. A well laid down principles on which to operate.

- Maintaining brand relevance requires commitment and the intention to focus on an organisation's values, mission, and goal.

- It is hard to succeed at branding without building a brand internally, therefore, every team member needs to be involved in the branding effort.

- An organisation's brand message should be uniform in style and tone, and consistent in delivery. This means expressing the brand personality in a way that inspires confidence and portrays reliability, both online and offline.

- Civil Society Organisations must realise that building a resilient brand that stands the test of time needs a commitment of time, money, effort, and other resources as such brands are growth enablers.

- A strong digital presence is also of the essence in building a formidable corporate brand.

\section{Conclusion}

Corporate branding is not a onetime event. It is a continuous and constant process, which builds up both conscious and subconscious opinions of the organisation as a whole, in the minds of its audience. A successful branding strategy is a secured foundation for corporate growth. It is defined by the organisation's mission, values, and objectives. Corporate branding is not only about the external aspects of branding. It also involves internal branding. Your brand identity won't mean much, if not backed up by quality service delivery from employees.

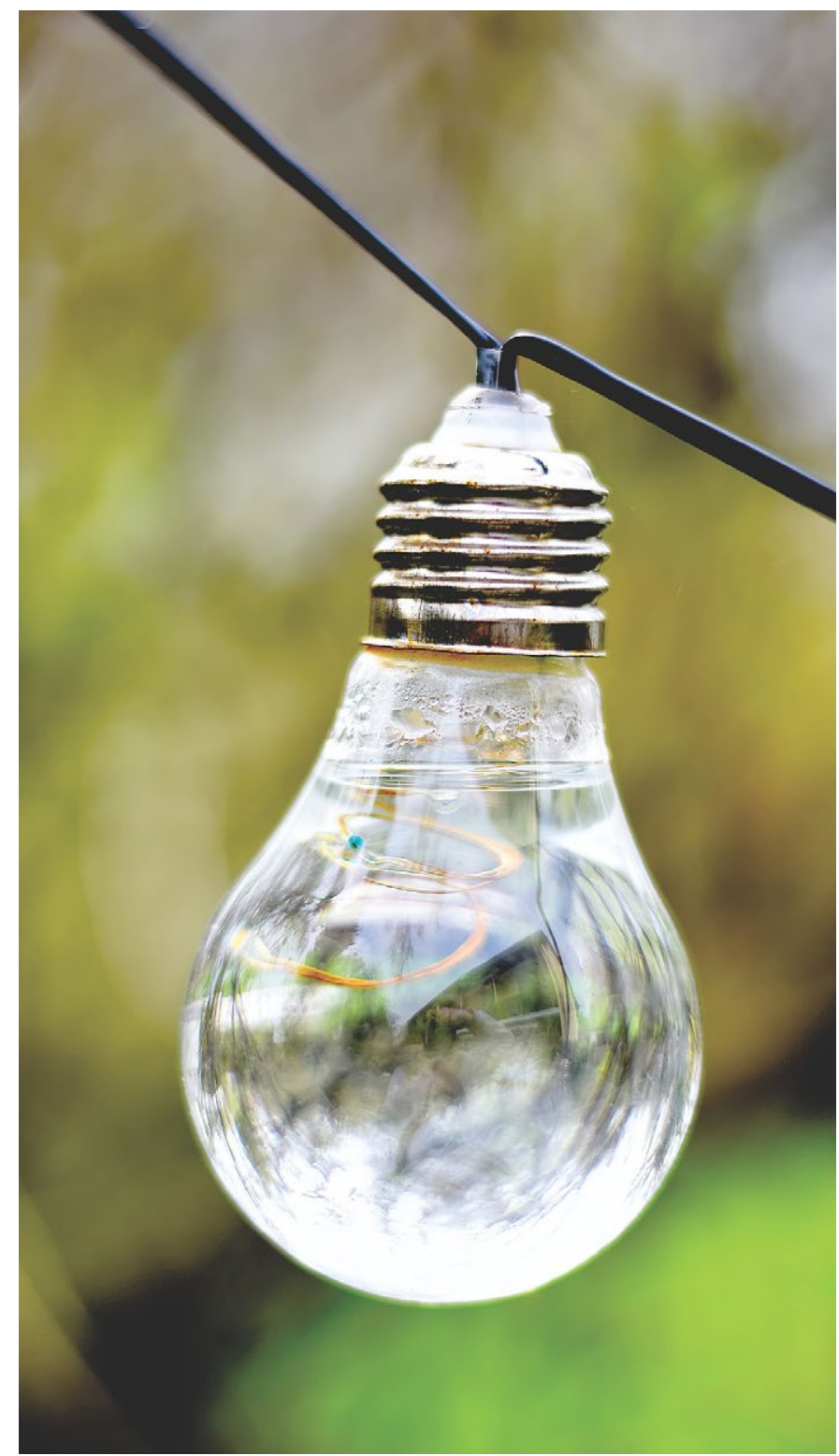

Image by Alexandra A life without animals is not worth living from Pixabay

Therefore, creating an ideal corporate culture is the first step. Every form of communication and or behaviour either builds or destroys corporate identity. Hence having a unique and consistent look and feel across every point of digital and/or social interaction is essential. A strong message, commanding visual identity, reliable team and valuable tools are a formidable bridge that inter-connects organisations and potential partners and invites brand advocates to help tell your story to the wider world. In other words, branding will make your organisation to be socially-inclusive, environmentally-sustainable, and economically-viable. 


\section{WACSI \\ Strengthening Civil Society}

WACSI All Rights Reserved

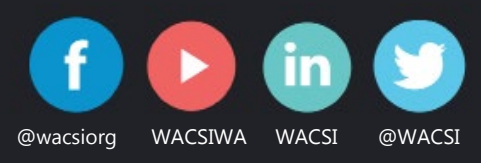

